\title{
Urban-Rural Differences in the Associations of Risk Factors With Epilepsy Based on the California Health Interview Survey: A Multiple Logistic Regression Analysis
}

\author{
Ke-Sheng Wang, ${ }^{1, *}$ Chun Xiang Mao, ${ }^{2}$ Xuefeng Liu, ${ }^{3}$ Alok Dwivedi, ${ }^{4}$ Javier Ordonez, ${ }^{4}$ Lewis R Rubin, ${ }^{2,4}$ \\ and Chun $\mathrm{Xu}^{2,4, *}$ \\ ${ }^{1}$ Department of Biostatistics and Epidemiology, College of Public Health, East Tennessee State University, Johnson City, Tennessee, USA \\ ${ }^{2}$ Department of Pediatrics, Paul L. Foster School of Medicine, Texas Tech University Health Sciences Center, El Paso, Texas, USA \\ ${ }^{3}$ Department of Systems Leadership and Effectiveness Science, School of Nursing, University of Michigan, Ann Arbor, Michigan, USA \\ ${ }^{4}$ Department of Biomedical Sciences, Paul L. Foster School of Medicine, Texas Tech University Health Sciences Center, El Paso, Texas, USA \\ "Corresponding authors: Ke-Sheng Wang, Department of Biostatistics and Epidemiology, College of Public Health, East Tennessee State University, Johnson City, Tennessee, USA. \\ Tel: +1-4234394481, Fax: +1-4234394606, E-mail: wangk@etsu.edu; Chun Xu, Department of Pediatrics, Paul L. Foster School of Medicine, Texas Tech University Health Sciences \\ Center, El Paso, Texas, USA. Tel: +1-9152154196, E-mail: chunx.xu@ttuhsc.edu
}

Received 2015 July 02; Revised 2015 August 20; Accepted 2015 October 07.

\begin{abstract}
Background: Previous studies provided inconsistent associations of smoking, stroke, and serious psychological distress (SPD) with epilepsy while urban-rural differences in the associations of risk factors with epilepsy are not well documented.

Objectives: This study aimed to evaluate the associations of lifestyle, health conditions, and SPD with epilepsy and to examine whether the associations differ between urban and rural areas.

Patients and Methods: A total of 604 adults with epilepsy and 42416 controls were selected from the 2005 California Health Interview Survey. Weighted univariate and multiple logistic regression analyses were used to estimate the associations of potential factors (behavioral factors, SPD, social factors and health conditions) with epilepsy. The odds ratios (ORs) with $95 \%$ confidence intervals (CIs) were estimated.

Results: The overall prevalence of epilepsy was $1.3 \%$ and the prevalence was higher in urban area than rural area (1.4 vs. $1.1 \%)$. The prevalence of SPD was $11 \%$ in cases and $4 \%$ in controls, respectively. The percentage of stroke was higher in cases than in controls ( $9 \%$ vs. 2\%). After adjusting for other factors using multiple logistic regression, current smoking, stroke, cancer, SPD and living in urban were positively significantly associated with epilepsy $(\mathrm{OR}=1.74,95 \% \mathrm{CI}=1.28-2.38 ; \mathrm{OR}=4.81,95 \% \mathrm{CI}=3.13-7.41 ; \mathrm{OR}=1.52,95 \% \mathrm{CI}=1.12$ 2.06; $\mathrm{OR}=2.02,95 \% \mathrm{CI}=1.39-2.92$, and $\mathrm{OR}=1.4,95 \% \mathrm{CI}=1.08-1.81$, respectively); while binge drinking was negatively associated with epilepsy $(\mathrm{OR}=0.65,95 \% \mathrm{CI}=0.43-0.99)$. Stratified by residence, in the urban area, current smoking and race were only associated with epilepsy. Stroke and SPD showed stronger association with epilepsy in the rural area $(\mathrm{OR}=7.63,95 \% \mathrm{CI}=3.68-15.8$, and $\mathrm{OR}=$ $3.14,95 \% \mathrm{CI}=1.52-6.47$, respectively) comparing with urban region $(\mathrm{OR}=4.51,95 \% \mathrm{CI}=2.79-7.28$ and $\mathrm{OR}=1.9,95 \% \mathrm{CI}=1.27-2.86$, respectively).

Conclusions: Smoking, stroke, and SPD were associated with epilepsy; while the associations differed between urban and rural areas.
\end{abstract}

Keywords: Epilepsy, Prevalence, Smoking, Stroke, Cancer, Binge Drinking

\section{Background}

Epilepsy is a category of neurological disorders in which cortical neuronal is disturbed, causing sporadic episodic lapses in brain function which may result in a wide variety of symptoms and sensations potentially including abnormal behavior and/or impaired consciousness. Epilepsy affects about 2 million Americans (1); while globally, it costs most countries up to $1 \%$ of their total national health care expenditure (2). Epilepsy may considerably negatively affect people's day-to-day functioning (3). The causes of epilepsy may be linked to various factors, genetic, developmental or acquired factors. A num- ber of potential factors have been reported to be associated with epilepsy, including reduced cognitive function, memory loss (4), adverse drug reactions to antiepileptic drugs (AEDs) (5), smoking among pregnant women with the disorder (6), cancer (7), psychosocial burden including anxiety and serious psychological distress (SPD) (8), employment status (9), stroke $(10,11)$, and depression (12). It has been systemically reviewed about the association between demographic, psychosocial, and condition-related factors and health-related quality of life, resource utilization or costs in adults with epilepsy (13).

Due to the high burden of epilepsy on society and in- 
dividual patient, identification of these risk factors is central to improve health care and quality of life for epilepsy patients. Furthermore, there are inconsistent findings related to smoking, stroke and SPD with epilepsy in some studies, especially due to small sample size and different designs (14). In addition, little is known about urban-rural differences in the associations of mental health and behavioral factors with epilepsy.

\section{Objectives}

We conducted a secondary data analysis with large sample size $(n=43020)$ using logistic regression models to estimate the associations of behavioral factors, SPD, social factors and health conditions with epilepsy and to examine whether such associations differ between urban and rural residential status.

\section{Patients and Methods}

\subsection{Study Population}

The California Health Interview Survey (CHIS) is conducted by a collaborative study of the University of California, Los Angeles (UCLA) center for health policy research, the California department of health services, and the public health institute. The 2005 CHIS data is from the third CHIS data collection cycle since 2001. From each household, one adult respondent aged 18 years or older was randomly selected. Details about the sampling design can be found at http://healthpolicy.ucla.edu/chis/design/Pages/overview.aspx In the current study, 43020 adults were included. For the CHIS 2005 data, the overall response rate was 26.9\%, which is calculated based on a $49.8 \%$ success rate in initial screening and $59.3 \%$ of respondents completing the entire survey. The data collection and analysis procedures were approved by the institutional review boards (IRBs) at the participant universities and agencies. The present study was approved by the IRB of authors' university.

\subsection{Measurements}

\subsubsection{Assessment of Epilepsy}

Subjects were considered to have had epilepsy if they responded "yes" to the question "Have you ever been told by a doctor that you have a seizure disorder or epilepsy?" In total, 604 adults with epilepsy and 42416 controls were available for the 2005 CHIS.

\subsubsection{Behavioral Factors}

Smoking status was categorized as never smoking, current smoking, or past smoking. Other behavioral factors were coded as yes/no, including binge drinking and obesity. Adult was considered to have obesity when the body mass index (BMI) was 30.0 or greater. Binge drinking was defined for women when the individuals had 4 or more drinks at one time during the last 30 days and for men when the individuals had 5 or more drinks at one time during the last 30 days (15).

\subsection{3. $S P D$}

SPD has been used as a nonspecific psychometrically validated measure of psychological distress to discriminate among diagnostic and statistical manual of mental disorders, fourth edition (DSM-IV) cases from non-cases (16, 17). SPD is defined by the Kessler 6 (K6) scale, which consists of 6 questions asking how often during the past 30 days a person felt: "so sad that nothing could cheer them up," "nervous," "restless," "hopeless," "worthless," or that "everything was an effort." Responses are scored from 0 (none of time) to 4 (all the time) and then the scores are summed to produce a total score (0 to 24); a total score of 13 or greater defines SPD (16). The K6 scale has been widely used to screen for DSM-IV mood and anxiety disorders in the previous studies $(18,19)$.

\subsubsection{Social Factors}

Gender was coded as either male or female based on self-report. Age was categorized as young (18 - 44 years), middle aged ( 45 - 64 years), and elderly (65 years or older). Employment status was classified as yes or no. Race was made of two subgroups: white and non-white. Residence was coded as urban and rural based on zip code.

\subsubsection{Health Condition}

Individuals were considered to have experienced a stroke if they responded "yes" to the question "doctor ever told had a stroke". Adults were considered to have had a cancer if they responded "yes" to the question "doctor ever told had cancer".

\subsection{Statistical Analysis}

In this cross-sectional study, we referred subjects with epilepsy as cases and subjects without epilepsy as controls. Sas Proc Surveymeans was used to estimate the overall prevalence and Sas Proc Surveyfreq was used to estimate population proportions in cases and controls for behavioral factors, health conditions, SPD, and social factors. The chi-square test was applied to compare the prevalence of epilepsy across gender, age and race. Then the Sas Proc 
Surveylogistic procedure was used to estimate odds ratios (ORs) and 95\% confidence intervals (CIs) for the relation between potential risk factors and epilepsy. First, simple logistic regression (univariate logistic regression analysis) was used to examine the unadjusted association of each potential factor with epilepsy. After that, multiple logistic regression analysis was used to simultaneously adjust for all potential factors of epilepsy using enter method. First order effect modification/interaction with residential status was explored in relation with all important variables. In view of significant effect modification of residential status, a stratified analysis by residential status was performed to determine the association of risk factors with epilepsy using multiple logistic regressions. All the analyses were performed using SAS statistical software, version 9.2 (SAS Institute, Cary, NC, USA). A jackknife method was used to properly estimate confidence intervals considering the survey's multistage sampling design.

\section{Results}

\subsection{Subjects Characteristics and Prevalence}

The characteristics of the epilepsy cases and controls are listed in Table 1 . The prevalence of current smoking was higher in cases than that in controls (24\% vs. $15 \%$ ). There were $25 \%$ of cases and $21 \%$ of controls who were obese. The percentage of SPD in cases and in controls was $11 \%$ and $4 \%$, respectively. For the elders (65 years of age or older), the percentage was lower in cases than in controls (9\% vs. $15 \%$ ). Most subjects were unemployed (52\%) in the patient group, but fewer controls were unemployed (39\%). For health factors, prevalence of stroke was higher in cases (9\%) compared to the control group (2\%) and prevalence of cancer was higher in cases than controls ( $11 \%$ vs. $8 \%$ ). The prevalence of epilepsy by gender, age and race is presented in Table 2 . The overall prevalence of epilepsy was $1.3 \%$ (1.2\% for males and $1.5 \%$ for females, respectively); while the prevalence was higher in urban area than that in rural area (1.4 vs. $1.1 \%)$. The prevalence in stroke (5.4\%) was higher than those without stroke, while the prevalence in SPD (3.7\%) was higher than those without SPD (1.2\%).

\subsection{Logistic Regression Analysis for the Whole Sample}

Table 3 presents the results from both univariate and multiple logistic regression analyses. By univariate analyses, current smoking, stroke, cancer, SPD, older ages, and employment were associated with epilepsy. After adjusting for other factors using multiple logistic regression, current smoking, stroke, cancer, SPD and living in urban were still positively significantly associated with epilepsy (OR = $1.74,95 \% \mathrm{CI}=1.28-2.38 ; \mathrm{OR}=4.81,95 \% \mathrm{CI}=3.13-7.41 ; \mathrm{OR}=$
$1.52,95 \% \mathrm{CI}=1.12-2.06 ; \mathrm{OR}=2.02,95 \% \mathrm{CI}=1.39-2.92$, and $\mathrm{OR}=1.4,95 \% \mathrm{CI}=1.08-1.81$, respectively); while binge drinking was negatively associated with epilepsy $(\mathrm{OR}=0.65,95 \%$ $\mathrm{CI}=0.43$ - 0.99). In addition, middle-aged and elderly, employed were negatively associated with epilepsy $(\mathrm{OR}=0.79$, $95 \% \mathrm{CI}=0.63-0.99 ; \mathrm{OR}=0.21,95 \% \mathrm{CI}=0.13-0.33$; and $\mathrm{OR}=$ $0.56,95 \% \mathrm{CI}=0.43-0.72$, respectively).

\subsection{Interactions with Residential Status}

After adjusting for all potential risk factors in the multiple logistic regression models, age group, smoking, stroke, cancer status, obesity, SPD, race, and employment showed significant interactions $(\mathrm{P}<0.05)$ with residential status. Stroke, SPD, cancer, obesity and white race showed positive interactions with residential status $(\mathrm{P}<0.0001$ with $\mathrm{OR}=4.51 ; \mathrm{P}=0.0012$ with $\mathrm{OR}=1.93 ; \mathrm{P}=0.0284$ with $\mathrm{OR}=1.49 ; \mathrm{P}=0.0439$ with $\mathrm{OR}=1.28$; and $\mathrm{P}=0.0065$ with $\mathrm{OR}$ $=1.37$; respectively); while comparing with never smoking, current smoking revealed significant interaction with residential status $(\mathrm{P}=0.0004$ with $\mathrm{OR}=1.81)$. Thus, a stratified analysis by residential status was performed and reported in Table 4.

\subsection{Logistic Regression Analysis of Urban-Rural Differences}

The urban-rural differences in the associations of behavioral factors, health conditions, SPD, and social factors with epilepsy are shown in Table 4. Current smoking and race were only associated with epilepsy in urban area (OR $=1.77,95 \% \mathrm{CI}=1.26-2.49 ; \mathrm{OR}=1.34,95 \% \mathrm{CI}=1.03$ - 1.73). Age, stroke, cancer, SPD and employment were associated with epilepsy in both urban and rural areas; whereas stroke and SPD showed stronger association with epilepsy in the rural area $(\mathrm{OR}=7.63,95 \% \mathrm{CI}=3.68-15.8$, and $\mathrm{OR}=3.14,95 \% \mathrm{CI}=$ $1.52-6.47$, respectively) comparing with urban region (OR $=4.51,95 \% \mathrm{CI}=2.79-7.28$ and $\mathrm{OR}=1.9,95 \% \mathrm{CI}=1.27-2.86$, respectively).

\section{Discussion}

In this study, we found the prevalence of epilepsy was significantly higher in adults being current smoking, with stroke or SPD than in those without these conditions. After adjusting for covariates, we identified several factors (current smoking, stroke, cancer, and SPD) significantly associated with an increased odds for having epilepsy based on a total of 43020 adults. Especially, we found urban-rural differences in the association of several factors with epilepsy.

The overall prevalence of epilepsy in the California population was $1.3 \%$ (1.5\% for female and $1.2 \%$ for male), which is quite similar to those in previous studies $(20$, 21). Our findings further showed that the prevalence of 
Table 1. Characteristics of Cases and Controls ${ }^{\mathrm{a}}$

\begin{tabular}{|c|c|c|}
\hline Variables & Cases $(n=604)$ & Controls $(n=42416)$ \\
\hline \multicolumn{3}{|l|}{ Gender } \\
\hline Male & $211(46)$ & $17261(49)$ \\
\hline Female & $393(54)$ & $25155(51)$ \\
\hline \multicolumn{3}{|l|}{ Age group,y } \\
\hline $18-44$ & $228(56)$ & $16222(54)$ \\
\hline $45-64$ & $287(35)$ & $16450(31)$ \\
\hline$>65$ & $89(9)$ & $9744(15)$ \\
\hline \multicolumn{3}{|l|}{ Smoking status } \\
\hline Never & $292(51)$ & $23813(60)$ \\
\hline Current & $133(24)$ & $6033(15)$ \\
\hline Past & $179(25)$ & $12570(25)$ \\
\hline \multicolumn{3}{|l|}{ Binge drinking } \\
\hline No & $542(87)$ & $36335(82)$ \\
\hline Yes & $62(13)$ & $6081(18)$ \\
\hline \multicolumn{3}{|l|}{ Stroke } \\
\hline No & $525(91)$ & $41167(98)$ \\
\hline Yes & $79(9)$ & $1249(2)$ \\
\hline \multicolumn{3}{|l|}{ Cancer } \\
\hline No & $502(89)$ & $37520(92)$ \\
\hline Yes & $102(11)$ & $4896(8)$ \\
\hline \multicolumn{3}{|l|}{ Obesity } \\
\hline No & $453(75)$ & $33618(79)$ \\
\hline Yes & $151(25)$ & $8798(21)$ \\
\hline \multicolumn{3}{|l|}{ SPD } \\
\hline No & $513(89)$ & $40708(96)$ \\
\hline Yes & $83(11)$ & $1575(4)$ \\
\hline \multicolumn{3}{|l|}{ Employment } \\
\hline No & $363(52)$ & $19416(39)$ \\
\hline Yes & $241(48)$ & $23000(61)$ \\
\hline \multicolumn{3}{|l|}{ Residence } \\
\hline Rural & $117(10)$ & $7933(12)$ \\
\hline Urban & $487(90)$ & $34443(88)$ \\
\hline \multicolumn{3}{|l|}{ Race } \\
\hline White & $424(57)$ & $28555(52)$ \\
\hline Non-white & $180(43)$ & $13861(48)$ \\
\hline
\end{tabular}

Abbreviation: SPD, serious psychological distress.

${ }^{\mathrm{a}}$ Values are presented as No. (\%).

epilepsy in stroke (5.4\%) was higher than those without stroke (1.2\%) and also suggest that people with stroke are more likely (adjusted OR of 4.81) to have epilepsy com- pared with people without a history of stroke. A previous study has shown that stroke can cause epilepsy, especially in the elderly stroke is the most common cause of new- 
Table 2. The Prevalence of Epilepsy (\%) According to Considered Factors

\begin{tabular}{|c|c|c|c|c|c|}
\hline Variables & Total & No. of Cases & Prevalence, \% & 95\% CI & PValue \\
\hline \multicolumn{6}{|l|}{ Gender } \\
\hline Male & 17472 & 211 & 1.2 & $0.9-1.5$ & 0.259 \\
\hline Female & 25548 & 393 & 1.5 & $1.2-1.6$ & \\
\hline \multicolumn{6}{|l|}{ Age group, y } \\
\hline $18-44$ & 16450 & 228 & 1.4 & $1.1-1.6$ & 0.0026 \\
\hline $45-64$ & 16737 & 287 & 1.5 & $1.3-1.7$ & \\
\hline$>65$ & 9833 & 89 & 0.8 & $0.5-1.0$ & \\
\hline \multicolumn{6}{|l|}{ Smoking status } \\
\hline Never & 24105 & 292 & 1.1 & $0.9-1.3$ & 0.0002 \\
\hline Current & 6166 & 133 & 2.1 & $1.5-2.6$ & \\
\hline Past & 12749 & 179 & 1.4 & $1.1-1.7$ & \\
\hline \multicolumn{6}{|l|}{ Binge drinking } \\
\hline No & 36877 & 542 & 1.4 & $1.2-1.6$ & 0.00857 \\
\hline Yes & 6143 & 62 & 1.0 & $0.6-1.4$ & \\
\hline \multicolumn{6}{|l|}{ Stroke } \\
\hline No & 41692 & 525 & 1.2 & $1.1-1.4$ & $<0.0001$ \\
\hline Yes & 1249 & 79 & 5.4 & $3.7-7.1$ & \\
\hline \multicolumn{6}{|l|}{ Cancer } \\
\hline No & 38022 & 502 & 1.3 & $1.1-1.5$ & 0.0125 \\
\hline Yes & 4998 & 102 & 1.9 & $1.4-2.3$ & \\
\hline \multicolumn{6}{|l|}{ Obesity } \\
\hline No & 34071 & 453 & 1.3 & $1.1-1.5$ & 0.0967 \\
\hline Yes & 8949 & 151 & 1.5 & $1.2-1.8$ & \\
\hline \multicolumn{6}{|l|}{ SPD } \\
\hline No & 41221 & 513 & 1.2 & $1.0-1.4$ & $<0.0001$ \\
\hline Yes & 1658 & 83 & 3.7 & $2.6-4.8$ & \\
\hline \multicolumn{6}{|l|}{ Employment } \\
\hline No & 19779 & 363 & 1.7 & $1.5-2.0$ & $<0.001$ \\
\hline Yes & 23241 & 241 & 1.1 & $0.8-1.3$ & \\
\hline \multicolumn{6}{|l|}{ Residence } \\
\hline Rural & 8090 & 117 & 1.1 & $0.8-1.3$ & 0.0869 \\
\hline Urban & 34930 & 487 & 1.4 & $1.2-1.6$ & \\
\hline \multicolumn{6}{|l|}{ Race } \\
\hline White & 28979 & 424 & 1.5 & $1.3-1.7$ & 0.0766 \\
\hline Non-white & 14041 & 180 & 1.2 & $0.9-1.4$ & \\
\hline Overall & 43020 & 604 & 1.3 & $0.8-1.5$ & \\
\hline
\end{tabular}

Abbreviation: SPD, serious psychological distress; CI, Confidence Interval.

onset epilepsy (22). Recently, the frequency of seizures in stroke victims was estimated to vary from 5 to $20 \%$ and stroke was positively associated with seizures and epilepsy (23). The incidence of post-stroke epilepsy in a European 
Table 3. Univariate and Multiple Logistic Regression Analyses for the Relationship Between All Potential Risk Factors and Epilepsy

\begin{tabular}{|c|c|c|c|c|c|c|}
\hline Variables & Crude OR & 95\% CI & PValue & Adjusted OR & 95\% CI & PValue \\
\hline \multicolumn{7}{|l|}{ Gender } \\
\hline Male & 1 & & & 1 & & \\
\hline Female & 1.15 & $0.89-1.48$ & 0.277 & 1.04 & $0.80-1.35$ & 0.772 \\
\hline \multicolumn{7}{|l|}{ Age group, y } \\
\hline $18-44$ & 1 & & & 1 & & \\
\hline $45-64$ & 1.09 & $0.87-1.37$ & 0.459 & 0.79 & $0.63-0.99$ & 0.0427 \\
\hline$>65$ & 0.49 & $0.33-0.72$ & 0.0003 & 0.21 & $0.13-0.33$ & $<0.0001$ \\
\hline \multicolumn{7}{|l|}{ Smoking status } \\
\hline Never & 1 & & & 1 & & \\
\hline Current & 1.89 & $1.39-2.57$ & $<0.0001$ & 1.74 & $1.28-2.38$ & 0.0005 \\
\hline Past & 1.19 & $0.90-1.58$ & 0.213 & 1.30 & $0.97-1.75$ & 0.0792 \\
\hline \multicolumn{7}{|l|}{ Binge drinking } \\
\hline No & 1 & & & 1 & & \\
\hline Yes & 0.73 & $0.49-1.07$ & 0.105 & 0.65 & $0.43-0.99$ & 0.0422 \\
\hline \multicolumn{7}{|l|}{ Stroke } \\
\hline No & 1 & & & 1 & & \\
\hline Yes & 4.51 & $3.15-6.46$ & $<0.0001$ & 4.81 & $3.13-7.41$ & $<0.0001$ \\
\hline \multicolumn{7}{|l|}{ Cancer } \\
\hline No & 1 & & & 1 & & \\
\hline Yes & 1.49 & $1.10-2.02$ & 0.0096 & 1.52 & $1.12-2.06$ & 0.0069 \\
\hline \multicolumn{7}{|l|}{ Obesity } \\
\hline No & 1 & & & 1 & & \\
\hline Yes & 1.24 & $0.98-1.57$ & 0.0692 & 1.19 & $0.94-1.50$ & 0.149 \\
\hline \multicolumn{7}{|l|}{ SPD } \\
\hline No & 1 & & & 1 & & \\
\hline Yes & 3.14 & $2.21-4.49$ & $<0.0001$ & 2.02 & $1.39-2.92$ & 0.0002 \\
\hline \multicolumn{7}{|l|}{ Employment } \\
\hline No & 1 & & & 1 & & \\
\hline Yes & 0.60 & $0.47-0.77$ & $<0.0001$ & 0.56 & $0.43-0.72$ & $<0.0001$ \\
\hline \multicolumn{7}{|l|}{ Residence } \\
\hline Rural & 1 & & & 1 & & \\
\hline Urban & 1.26 & $0.97-1.63$ & 0.0876 & 1.40 & $1.08-1.81$ & 0.0117 \\
\hline \multicolumn{7}{|l|}{ Race } \\
\hline Non-white & 1 & & & 1 & & \\
\hline White & 1.27 & $0.98-1.63$ & 0.0613 & 1.37 & $1.08-1.73$ & 0.0096 \\
\hline
\end{tabular}

Abbreviation: CI, confidence interval; OR, odds ratio; SPD, serious psychological distress.

population was $8.2 \%$, which is higher than that in previous studies ( 2 - 4\%) (10). Stroke and epilepsy coexist, so the mechanisms underlying this association need further in- vestigation (24).

Epilepsy patients reported to have greater SPD than controls ( $11 \%$ vs. $4 \%$ ) which is in the line with previous 
Table 4. Multiple Logistic Regression Analyses for the Relationship Between All Potential Risk Factors and Epilepsy by Urban and Rural Areas

\begin{tabular}{|c|c|c|c|c|c|c|}
\hline Variables & Adjusted OR(Rural Residence) & 95\% CI & PValue & Adjusted OR(Urban Residence) & 95\% CI & PValue \\
\hline \multicolumn{7}{|l|}{ Gender } \\
\hline Male & 1 & & & 1 & & \\
\hline Female & 1.30 & $0.70-2.41$ & 0.4 & 1.02 & $0.78-1.33$ & 0.908 \\
\hline \multicolumn{7}{|l|}{ Age group, y } \\
\hline $18-44$ & 1 & & & 1 & & \\
\hline $45-64$ & 0.55 & $0.29-1.04$ & 0.0674 & 0.82 & $0.64-1.06$ & 0.126 \\
\hline$>65$ & 0.12 & $0.04-0.32$ & $<0.0001$ & 0.22 & $0.13-0.37$ & $<0.0001$ \\
\hline \multicolumn{7}{|l|}{ Smoking status } \\
\hline Never & 1 & & & 1 & & \\
\hline Current & 1.45 & $0.74-2.83$ & 0.277 & 1.77 & $1.26-2.49$ & 0.0011 \\
\hline Past & 1.51 & $0.67-3.41$ & 0.316 & 1.27 & $0.92-1.76$ & 0.146 \\
\hline \multicolumn{7}{|l|}{ Binge drinking } \\
\hline No & 1 & & & 1 & & \\
\hline Yes & 0.36 & $0.13-1.01$ & 0.0525 & 0.69 & $0.45-1.05$ & 0.0858 \\
\hline \multicolumn{7}{|l|}{ Stroke } \\
\hline No & 1 & & & 1 & & \\
\hline Yes & 7.63 & $3.68-15.8$ & $<0.0001$ & 4.51 & $2.79-7.28$ & $<0.0001$ \\
\hline \multicolumn{7}{|l|}{ Cancer } \\
\hline No & 1 & & & 1 & & \\
\hline Yes & 1.96 & $1.13-3.41$ & 0.0169 & 1.45 & $1.01-2.09$ & 0.0448 \\
\hline \multicolumn{7}{|l|}{ Obesity } \\
\hline No & 1 & & & 1 & & \\
\hline Yes & 0.90 & $0.48-1.70$ & 0.753 & 1.23 & $0.96-1.55$ & 0.089 \\
\hline \multicolumn{7}{|l|}{ SPDa } \\
\hline No & 1 & & & 1 & & \\
\hline Yes & 3.14 & $1.52-6.47$ & 0.002 & 1.90 & $1.27-2.86$ & 0.0019 \\
\hline \multicolumn{7}{|l|}{ Employment } \\
\hline No & 1 & & & 1 & & \\
\hline Yes & 0.36 & $0.19-0.67$ & 0.0013 & 0.58 & $0.44-0.76$ & 0.0001 \\
\hline \multicolumn{7}{|l|}{ Race } \\
\hline Non-white & 1 & & & 1 & & \\
\hline White & 1.81 & $0.79-4.15$ & 0.16 & 1.34 & $1.03-1.73$ & 0.0266 \\
\hline
\end{tabular}

Abbreviation: CI, confidence interval; OR, odds ratio; SPD, serious psychological distress.

observations that depression and anxiety were associated with epilepsy or seizure disorders $(20,25)$. Psychiatric disorders such as anxiety and depression have been more common comorbidities with epilepsy than in the general population (24). Few studies have investigated the effects of SPD on epilepsy. Previous study (8) reported that the adjusted OR for SPD with epilepsy was 2.24 , which is sim- ilar to our results (adjusted $\mathrm{OR}=2.02$ ). Our results further indicated that the prevalence of epilepsy in SPD (3.7\%) is significantly higher than subjects without SPD (1.2\%). Increasing evidence suggests that epilepsy patients without seizure control may have higher levels of psychological distress, a deleterious cycle of loss of self-efficacy, and social disadvantage (26). In light of this significant association 
between SPD and epilepsy, SPD was found as the strongest predictors of health-related quality of life among epilepsy patients (27), a rehabilitation approach and partnership with general practitioners and nurses are warranted to assess psychological distress and reduce distress for people with epilepsy $(8,26)$.

The current findings also provide additional evidence of a strong association between cancer and epilepsy. Previous study revealed that the lifetime risk of having epileptic seizures may increase significantly for patients with cancer; while patients with primary brain tumors may increase a lifetime risk of epilepsy about $20-80 \%$ (28). The treatment for seizures in patients with cancer is multifaceted and may involve surgery, radiation, chemotherapy, and antiepileptic drugs.

Cigarette smoking is associated with increased risk of epilepsy, which is consistent with previous studies (21, 29, 30 ). The present study further adds to this finding and suggests that current smoking is associated with epilepsy, particularly in urban residence in California, indicating the complex effect of smoking on epilepsy. It has been proposed that the studies on the association between tobacco smoking and seizures or epilepsy are insufficient and future works on testing unique constituents of tobacco smoke and smoking cessation agents and better understanding of their mechanisms of action will be required to deeply understand the underlying pathophysiology of seizures and epilepsy, which may lead to the development of more effective treatments (30). Previous studies suggested that mild to moderate alcohol consumption may decrease risk of seizures $(31,32)$ or moderate alcohol use did not have association with seizure or epilepsy (29). Furthermore, binge drinking during pregnancy (11 16 weeks gestation) may be associated with the development of seizures in infants (33). Another study reported a dose-response relationship between the daily amount of alcohol use and the probability of the onset of epilepsy (34). Few studies have focused on the binge drinking with epilepsy. In the present study, multiple logistic regression analyses showed that binge drinking was negatively associated with epilepsy in the entire cohort and separate group analysis based on residency status.

The finding of increasing of unemployment rates among patients with epilepsy also added to previous observations. It has been reported that the full-time employment rates for patients with epilepsy were lower in various populations reported in Australia (35), and Malaysia (36). However, only $42 \%$ of adults with epilepsy reported employment compared with $70 \%$ of people without epilepsy in a U.S. population (37). The findings from our current study demonstrated that employment is a reduced risk for having epilepsy (Table 2). Therefore, it is important to understand employment patterns of people with epilepsy, which inform optimization of legislative, pharmacological, and nonpharmacological health strategies. To our knowledge, no study attempted to investigate the urbanrural differences in the associations of behavioral factors, health conditions, SPD, and social factors with epilepsy in the U.S. population. The present study provided new findings on current smoking and race were associated with epilepsy only in urban residence; while age, stroke, cancer, SPD and employment were associated with epilepsy in both urban and rural areas; whereas stroke and SPD showed stronger association with epilepsy in the rural area compared to urban region.

The study has several strengths such as the diversity of the population. For example, five languages (English, Spanish, Mandarin Chinese and Cantonese Chinese, Vietnamese, and Korean) facilitated inclusion in subjects who could neither speak English nor speak English well enough to otherwise participate. Furthermore, this large subject sample was randomly selected and included comprehensive information with a wide age range on epilepsy and social, behavioral, and health characteristics. The large sample made us possible to adjust for numerous factors. Moreover, we provided the prevalence estimates for epilepsy in lifestyle, health condition, SPD and urban and rural areas. In addition, we examined the urban-rural differences in the associations of behavioral factors, health conditions, SPD, and social factors with epilepsy in the California population.

Several limitations need to be acknowledged. First, a cross-sectional design cannot make decision about the causal relationships between these potential factors and epilepsy. Second, for a telephone survey, the institutionalized adults, who did not have a landline telephone or cell phone, and who could not answer the phone due to other reasons were impossible to be included, which may cause a potential selection bias between participants and nonparticipants. For instance, younger adults may have higher chance to possess a phone and answer the call. In addition, self-reported data may be subject to misclassification.

Importantly, the epidemiology of epilepsy has been widely used to identify the frequency, causes, and progress of epilepsy. Only $20-30 \%$ of epilepsy cases have a clearly etiological acquired cause (such as head trauma, stroke). The evidence suggests that there is a twofold to fourfold increase in epilepsy risk in first degree relatives and 70\% heritability derived from twin studies of epilepsies without known cause (38). A number of candidate genes such as SLC2A1, STXBP1, and SCN1A have been identified to be associated with epilepsy (39). In the near future, research discoveries on epidemiology, genetics, and epigenetic mechanisms will continue to drive our inextricable move towards 
prevention, high-throughput genetic diagnosis, targeted therapies, and personalized medicine for patients who suffer from epilepsy.

In conclusion, we identified a number of potential factors associated with epilepsy, including current smoking, stroke, cancer, unemployment and SPD; while the associations differed between urban and rural areas. Intervention strategies that target risk reduction of epilepsy may be tailored accordingly.

\section{Acknowledgments}

The authors are grateful to the support of Data from the 2005 California Health Interview Survey.

\section{Footnote}

Authors' Contribution: Ke-Sheng Wang, Chun Xiang Mao, and Chun $\mathrm{Xu}$ managed the literature searches and analyses, edited the references, and wrote the draft of the manuscript. Xuefeng Liu offered critical guidance on the statistical analysis and contributed for statistical expertise and improvement of the manuscript. Alok Dwivedi, Javier Ordonez, and Lewis R Rubin provided a substantive review of the manuscript. All authors read and approved the manuscript.

\section{References}

1. Hirtz D, Thurman DJ, Gwinn-Hardy K, Mohamed M, Chaudhuri AR, Zalutsky R. How common are the "common" neurologic disorders?.Neurology. 2007;68(5):326-37. doi: 10.1212/01.wnl.0000252807.38124.a3. [PubMed: 17261678]

2. Kotsopoulos IA, Evers SM, Ament AJ, de Krom MC. Estimating the costs of epilepsy: an international comparison of epilepsy cost studies. Epilepsia. 2001;42(5):634-40. [PubMed: 11380571].

3. Baker GA. Health-related quality-of-life issues: optimizing patient outcomes. Neurology. 1995;45(3 Suppl 2):S29-34. [PubMed: 7898743].

4. Vingerhoets G. Cognitive effects of seizures. Seizure. 2006;15(4):221-6. doi:10.1016/j.seizure.2006.02.012. [PubMed:16546410].

5. Wong IC, Lhatoo SD. Adverse reactions to new anticonvulsant drugs. Drug Saf. 2000;23(1):35-56. [PubMed: 10915031].

6. Harden CL, Hopp J, Ting TY, Pennell PB, French JA, Allen Hauser W, et al. Management issues for women with epilepsy-Focus on pregnancy (an evidence-based review): I. Obstetrical complications and change in seizure frequency: Report of the Quality Standards Subcommittee and Therapeutics and Technology Assessment Subcommittee of the American Academy of Neurology and the American Epilepsy Society. Epilepsia. 2009;50(5):1229-36. doi: 10.1111/j.1528-1167.2009.02128.x. [PubMed: 19496807]

7. Brogna C, Gil Robles S, Duffau H. Brain tumors and epilepsy. Expert Rev Neurother. 2008;8(6):941-55. doi: 10.1586/14737175.8.6.941. [PubMed: 18505359].

8. Layne Moore J, Elliott JO, Lu B, Klatte ET, Charyton C. Serious psychological distress among persons with epilepsy based on the $2005 \mathrm{Cal}$ ifornia Health Interview Survey. Epilepsia. 2009;50(5):1077-84. doi: 10.1111/j.1528-1167.2008.01996.x. [PubMed: 19260944].
9. Alanis-Guevara I, Pena E, Corona T, Lopez-Ayala T, Lopez-Meza E, LopezGomez M. Sleep disturbances, socioeconomic status, and seizure control as main predictors of quality of life in epilepsy. Epilepsy Behav. 2005;7(3):481-5. doi: 10.1016/j.yebeh.2005.06.010. [PubMed: 16098815].

10. Jungehulsing GJ, Heuschmann PU, Holtkamp M, Schwab S, Kolominsky-Rabas PL. Incidence and predictors of post-stroke epilepsy. Acta Neurol Scand. 2013;127(6):427-30. doi: 10.1111/ane.12070. [PubMed: 23398544].

11. Kaiboriboon K, Bakaki PM, Lhatoo SD, Koroukian S. Incidence and prevalence of treated epilepsy among poor health and low-income Americans. Neurology. 2013;80(21):1942-9. doi: 10.1212/WNL.ob013e318293e1b4. [PubMed: 23616158].

12. Ramaratnam S, Baker GA, Goldstein LH. Psychological treatments for epilepsy. Cochrane Database Syst Rev. 2008(3):Cd002029. doi: 10.1002/14651858.CD002029.pub3. [PubMed: 18646083].

13. Taylor RS, Sander JW, Taylor RJ, Baker GA. Predictors of health-related quality of life and costs in adults with epilepsy: a systematic review. Epilepsia. 2011;52(12):2168-80. doi: 10.1111/j.1528-1167.2011.03213.x. [PubMed: 21883177].

14. Lacey CJ, Salzberg MR, D'Souza WJ. Risk factors for psychological distress in community-treated epilepsy. Epilepsy Behav. 2014;35:1-5. doi: 10.1016/j.yebeh.2014.03.025. [PubMed: 24785427].

15. Banta JE, Przekop P, Haviland MG, Pereau M. Binge drinking among California adults: results from the 2005 California Health Interview Survey. Am J Drug Alcohol Abuse. 2008;34(6):801-9. doi: 10.1080/00952990802491571. [PubMed: 19016186].

16. Kessler RC, Andrews G, Colpe LJ, Hiripi E, Mroczek DK, Normand SL, et al. Short screening scales to monitor population prevalences and trends in non-specific psychological distress. Psychol Med. 2002;32(6):959-76. [PubMed: 12214795].

17. Kessler RC, Barker PR, Colpe LJ, Epstein JF, Gfroerer JC, Hiripi E, et al. Screening for serious mental illness in the general population. Arch Gen Psychiatry. 2003;60(2):184-9. [PubMed:12578436].

18. Baggaley RF, Ganaba R, Filippi V, Kere M, Marshall T, Sombie I, et al. Detecting depression after pregnancy: the validity of the K10 and K6 in Burkina Faso. Trop Med Int Health. 2007;12(10):1225-9. doi: 10.1111/j.13653156.2007.01906.x. [PubMed: 17956505].

19. Swartz JA, Lurigio AJ. Screening for serious mental illness in populations with co-occurring substance use disorders: Performance of the K6 scale. J Subst Abuse Treat. 2006;31(3):287-96. doi: 10.1016/j.jsat.2006.04.009. [PubMed: 16996391].

20. Kobau R, Zahran H, Grant D, Thurman DJ, Price PH, Zack MM. Prevalence of active epilepsy and health-related quality of life among adults with self-reported epilepsy in California: California Health Interview Survey, 2003. Epilepsia. 2007;48(10):1904-13. doi:10.1111/j.15281167.2007.01161.x. [PubMed: 17565591].

21. Elliott JO, Lu B, Moore JL, McAuley JW, Long L. Exercise, diet, health behaviors, and risk factors among persons with epilepsy based on the California Health Interview Survey, 2005. Epilepsy Behav. 2008;13(2):307-15. doi: 10.1016/j.yebeh.2008.04.003. [PubMed: 18490199].

22. Rowan AJ, Epilepsy Foundation of A. Epilepsy in older adults. Common morbidities influence development, treatment strategies, and expected outcomes. Geriatrics. 2005;60(12):30-2. [PubMed:16343034].

23. Lamy C. [Epilepsy and stroke]. Rev Neurol (Paris). 2008;164(10):841-5. doi: 10.1016/j.neurol.2008.07.006. [PubMed: 18755487].

24. Seidenberg M, Pulsipher DT, Hermann B. Association of epilepsy and comorbid conditions. Future Neurol. 2009;4(5):663-8. doi: 10.2217/fnl.09.32. [PubMed: 20161538].

25. Kimiskidis VK, Triantafyllou NI, Kararizou E, Gatzonis SS, Fountoulakis KN, Siatouni A, et al. Depression and anxiety in epilepsy: the association with demographic and seizure-related variables. Ann Gen Psychiatry. 2007;6:28. doi:10.1186/1744-859X-6-28. [PubMed: 17971199]. 
26. Ridsdale L. The social causes of inequality in epilepsy and developing a rehabilitation strategy: a U.K.-based analysis. Epilepsia. 2009;50(10):2175-9. doi: 10.1111/j.1528-1167.2009.02150.x. [PubMed: 19490033].

27. Gilliam F, Hecimovic H, Sheline Y. Psychiatric comorbidity, health, and function in epilepsy. Epilepsy Behav. 2003;4 Suppl 4:S26-30. [PubMed: 14654425].

28. Weller M, Stupp R, Wick W. Epilepsy meets cancer: when, why, and what to do about it?. Lancet Oncol. 2012;13(9):e375-82. doi: 10.1016/s1470-2045(12)70266-8. [PubMed: 22935237].

29. Dworetzky BA, Bromfield EB, Townsend MK, Kang JH. A prospective study of smoking, caffeine, and alcohol as risk factors for seizures or epilepsy in young adult women: data from the Nurses' Health Study II. Epilepsia. 2010;51(2):198-205. doi: 10.1111/j.1528-1167.2009.02268.x. [PubMed: 19694796].

30. Rong L, Frontera AJ, Benbadis SR. Tobacco smoking, epilepsy, and seizures. Epilepsy Behav. 2014;31:210-8. doi:10.1016/j.yebeh.2013.11.022. [PubMed: 24441294].

31. Kannel WB, Ellison RC. Alcohol and coronary heart disease: the evidence for a protective effect. Clin Chim Acta. 1996;246(1-2):59-76. [PubMed: 8814971].

32. Hillbom M, Pieninkeroinen I, Leone M. Seizures in alcohol-dependent patients: epidemiology, pathophysiology and management. CNS Drugs. 2003;17(14):1013-30. [PubMed: 14594442].

33. Sun Y, Strandberg-Larsen K, Vestergaard M, Christensen J, Nybo Andersen AM, Gronbaek M, et al. Binge drinking during pregnancy and risk of seizures in childhood: a study based on the Danish National Birth Cohort. Am J Epidemiol. 2009;169(3):313-22. doi: 10.1093/aje/kwn334. [PubMed: 19064645].

34. Samokhvalov AV, Irving $\mathrm{H}$, Mohapatra S, Rehm J. Alcohol consumption, unprovoked seizures, and epilepsy: a systematic review and meta-analysis. Epilepsia. 2010;51(7):1177-84. doi: 10.1111/j.15281167.2009.02426.x. [PubMed: 20074233].

35. Bellon M, Walker C, Peterson C, Cookson P. The "E" word: epilepsy and perceptions of unfair treatment from the 2010 Australian Epilepsy Longitudinal Survey. Epilepsy Behav. 2013;27(1):251-6. doi: 10.1016/j.yebeh.2013.01.016. [PubMed: 23453531].

36. Lim KS, Wo SW, Wong MH, Tan CT. Impact of epilepsy on employment in Malaysia. Epilepsy Behav. 2013;27(1):130-4. doi: 10.1016/j.yebeh.2012.12.034. [PubMed: 23416283].

37. Libby AM, Ghushchyan V, McQueen RB, Slejko JF, Bainbridge JL, Campbell JD. Economic differences in direct and indirect costs between people with epilepsy and without epilepsy. Med Care. 2012;50(11):92833. doi: 10.1097/MLR.0b013e31826c8613. [PubMed: 23047781].

38. Hildebrand MS, Dahl HH, Damiano JA, Smith RJ, Scheffer IE, Berkovic SF. Recent advances in the molecular genetics of epilepsy. $J$ Med Genet. 2013;50(5):271-9. doi:10.1136/jmedgenet-2012-101448. [PubMed: 23468209].

39. Linehan C, Tellez-Zenteno JF, Burneo JG, Berg AT. Future directions for epidemiology in epilepsy. Epilepsy Behav. 2011;22(1):112-7. doi: 10.1016/j.yebeh.2011.06.006. [PubMed: 21820360]. 